\title{
Correction to: Single-Cell RNA Sequencing of the Adult Mammalian Heart - State of the Art and Future Perspectives
}

\author{
Monika M. Gladka, PhD ${ }^{1,2}$
}

Published online: 2 April 2021

(C) Springer Science+Business Media, LLC, part of Springer Nature 2021

\section{Correction to: Current Heart Failure Reports 2021. https://doi.org/10.1007/s11897-021-00504-3}

After the publication of the original article, we noticed that we need a correction in Fig. 2. In the part of the table containing human studies, in Nomura et al. (2018), in the column indicating the type of samples, sham and TAC was now correctly replaced with healthy and DCM. Please see below the corrected version. We apologize for any inconvenience that this may have caused.

Publisher's Note Springer Nature remains neutral with regard to jurisdictional claims in published maps and institutional affiliations.

The online version of the original article can be found at https://doi.org/ 10.1007/s11897-021-00504-3

Monika M. Gladka, PhD

m.gladka@hubrecht.eu; m.m.gladka@amsterdamumc.nl

1 Hubrecht Institute, Royal Netherlands Academy of Arts and Sciences (KNAW) and University Medical Centre, PO Box 85164, 3508, AD Utrecht, The Netherlands

2 Department of Medical Biology, Amsterdam University Medical Center, Amsterdam, The Netherlands 


\begin{tabular}{|c|c|c|c|c|c|}
\hline mouse & study & $\begin{array}{l}\text { living cells vs } \\
\text { frozen nuclei }\end{array}$ & $\begin{array}{l}\text { healthy vs } \\
\text { diseased }\end{array}$ & platform & application \\
\hline & $\begin{array}{r}\text { Gladka et al.(2018) } \\
\text { Circulation }\end{array}$ & $\begin{array}{l}\text { living cells } \\
\mathrm{CM}\end{array}$ & $\begin{array}{l}\text { sham } \\
\text { IR }\end{array}$ & FACS & $\begin{array}{l}\text { cellular } \\
\text { heterogeneity }\end{array}$ \\
\hline & $\begin{array}{r}\text { Skelly et al.(2018) } \\
\text { Cell Reports }\end{array}$ & $\begin{array}{l}\text { living cells } \\
\text { non-CM }\end{array}$ & healthy & FACS & $\begin{array}{l}\text { cellular } \\
\text { communication }\end{array}$ \\
\hline & $\begin{array}{r}\text { Nomura et al.(2018) } \\
\text { Nat. Comm. }\end{array}$ & $\begin{array}{l}\text { living cells } \\
\mathrm{CM}\end{array}$ & $\begin{array}{l}\text { sham } \\
\text { TAC }\end{array}$ & $\begin{array}{l}\text { manual } \\
\text { pickup }\end{array}$ & $\begin{array}{l}\text { network and } \\
\text { trajectory analysis }\end{array}$ \\
\hline & $\begin{array}{r}\text { Kretzschmar et al. } \\
\text { (2018) PNAS }\end{array}$ & living cells & $\begin{array}{l}\text { sham } \\
\mathrm{IR} \text { and } \mathrm{MI}\end{array}$ & FACS & $\begin{array}{l}\text { Identification } \\
\text { of rare cells }\end{array}$ \\
\hline & $\begin{array}{r}\text { Ren et al. (2020) } \\
\text { Circulation }\end{array}$ & living cells & $\begin{array}{l}\text { sham } \\
\text { TAC }\end{array}$ & ICELL8 & $\begin{array}{l}\text { network and } \\
\text { trajectory analysis }\end{array}$ \\
\hline & $\begin{array}{l}\text { Yekelchyk et al. (2019) } \\
\text { Basic Res. Cardiol. }\end{array}$ & $\begin{array}{l}\text { living cells } \\
\mathrm{CM}\end{array}$ & $\begin{array}{l}\text { sham } \\
\text { TAC }\end{array}$ & ICELL8 & $\begin{array}{l}\text { cellular } \\
\text { heterogeneity }\end{array}$ \\
\hline Adult mammalian & $\begin{array}{r}\text { Wang et al. (2020) } \\
\text { Nat. Comm. }\end{array}$ & living cells & healthy & ICELL8 & $\begin{array}{l}\text { network and } \\
\text { trajectory analysis }\end{array}$ \\
\hline & $\begin{array}{r}\text { Vidal et al. (2019) } \\
\text { JCl Insights }\end{array}$ & nuclei & $\begin{array}{l}\text { healthy } \\
\text { and aging }\end{array}$ & 10x Genomics & $\begin{array}{l}\text { cellular } \\
\text { heterogeneity }\end{array}$ \\
\hline & $\begin{array}{r}\text { Zhang et al. (2019) } \\
\text { Cell Discov. }\end{array}$ & nuclei & $\begin{array}{l}\text { healthy } \\
\text { and } \mathrm{Ml}\end{array}$ & $10 x$ Genomics & $\begin{array}{l}\text { Identification } \\
\text { of rare cells }\end{array}$ \\
\hline & $\begin{array}{l}\text { See et al.(2017) } \\
\text { Nat.Comm. }\end{array}$ & $\begin{array}{l}\text { nuclei } \\
\text { CM }\end{array}$ & $\begin{array}{l}\text { sham } \\
\text { TAC }\end{array}$ & IFC system & $\begin{array}{l}\text { network and } \\
\text { trajectory analysis }\end{array}$ \\
\hline & $\begin{array}{l}\text { Li et al. (2019) } \\
\text { Eur. Heart J. }\end{array}$ & $\begin{array}{l}\text { living cells } \\
\text { non-CM }\end{array}$ & $\begin{array}{l}\text { healthy } \\
\text { and } \mathrm{Ml}\end{array}$ & $10 x$ Genomics & $\begin{array}{l}\text { cellular } \\
\text { heterogeneity }\end{array}$ \\
\hline & $\begin{array}{l}\text { Farbehi et al. } \\
\text { (2019) Elife }\end{array}$ & $\begin{array}{l}\text { living cells } \\
\text { non-CM }\end{array}$ & $\begin{array}{l}\text { healthy } \\
\text { and } \mathrm{MI}\end{array}$ & 10x Genomics & $\begin{array}{l}\text { cellular } \\
\text { communication }\end{array}$ \\
\hline \multirow[t]{7}{*}{ human } & study & $\begin{array}{l}\text { living cells vs } \\
\text { frozen nuclei }\end{array}$ & $\begin{array}{l}\text { healthy vs } \\
\text { diseased }\end{array}$ & platform & application \\
\hline & $\begin{array}{l}\text { Nomura et al. } \\
\text { (2018) Nat. Comm. }\end{array}$ & $\begin{array}{l}\text { living cells } \\
\text { CM }\end{array}$ & $\begin{array}{l}\text { healthy } \\
\text { DCM }\end{array}$ & $\begin{array}{l}\text { manual } \\
\text { pickup }\end{array}$ & $\begin{array}{l}\text { network and } \\
\text { trajectory analysis }\end{array}$ \\
\hline & $\begin{array}{l}\text { Wang et al. (2020) } \\
\text { Nat. Cell Biology }\end{array}$ & $\begin{array}{l}\text { living cells } \\
\text { all cells }\end{array}$ & $\begin{array}{l}\text { healthy, HF } \\
\text { and LVAD }\end{array}$ & ICELL8 & $\begin{array}{l}\text { cellular heterogeneity } \\
\text { and network analysis }\end{array}$ \\
\hline & $\begin{array}{l}\text { Selewa et al. } \\
\text { (2020) Sci. Rep. }\end{array}$ & $\begin{array}{l}\text { nuclei } \\
\text { CM }\end{array}$ & healthy & DropNuc-seq & $\begin{array}{l}\text { cellular } \\
\text { heterogeneity }\end{array}$ \\
\hline & $\begin{array}{r}\text { See et al.(2017) } \\
\text { Nat.Comm }\end{array}$ & $\begin{array}{l}\text { nuclei } \\
\text { CM }\end{array}$ & $\begin{array}{l}\text { non-failing } \\
\text { DCM }\end{array}$ & IFC system & $\begin{array}{l}\text { network and } \\
\text { trajectory analysis }\end{array}$ \\
\hline & $\begin{array}{l}\text { Litvinukova et al. } \\
\text { (2020) Nature }\end{array}$ & $\begin{array}{l}\text { living cells } \\
\text { nuclei }\end{array}$ & healthy & $\begin{array}{l}\text { 10x Genomics } \\
\text { FACS }\end{array}$ & $\begin{array}{l}\text { cellular heterogeneity } \\
\text { and communication }\end{array}$ \\
\hline & $\begin{array}{l}\text { Tucker et al. } \\
\text { (2020) Circulation }\end{array}$ & nuclei & healthy & 10x Genomics & $\begin{array}{l}\text { cellular } \\
\text { heterogeneity }\end{array}$ \\
\hline
\end{tabular}

Fig. 2 Overview of single-cell sequencing studies applied to adult healthy and diseased mouse or human heart. CM cardiomyocytes, IR ischemia/ reperfusion, MI myocardial infarction, TAC transaortic constriction, HF heart failure, LVAD left ventricular assist device, DCM dilated cardiomyopathy 